\title{
Fire, Defoliation, and Competing Species Alter Aristida purpurea Biomass, Tiller, and Axillary Bud Production
}

\author{
M. L. Russell, ${ }^{1}$ L. T. Vermeire, ${ }^{2}$ N. A. Dufek, ${ }^{1}$ and D. J. Strong ${ }^{3}$ \\ Authors are ${ }^{1}$ Graduate Research Assistant, Range Science Program, School of Natural Resources, North Dakota State University, Fargo, ND 58105, USA; \\ and ${ }^{2}$ Ecologist and ${ }^{3}$ Range Technician, USDA-ARS Fort Keogh Livestock and Range Research Laboratory, Miles City, MT 59301, USA.
}

\begin{abstract}
Aristida purpurea (purple threeawn) is a competitive native perennial grass with monoculturistic tendencies and poor palatability. We examined effects of fire, defoliation, and interspecific/intraspecific planting for 1) threeawn responses in the presence of threeawn, Bouteloua gracilis, or Pascopyrum smithii, and 2) B. gracilis and P. smithii response with threeawn. Biomass, aboveground production, tillers, and axillary buds were analyzed following two fire and four clipping treatments applied to three species-pair combinations in a completely randomized factorial design with nine replications. Fire killed 36\% of threeawn. Fire reduced surviving threeawn biomass $61 \%$ and reduced production $27 \%$. Threeawn production was greatest when neither plant was clipped and least when competing species were moderately clipped, or when both plants were severely clipped. Tiller counts of burned threeawn were similar among clipping treatments, and less than non-clipped or moderately clipped plants not burned. Fire decreased threeawn axillary buds on average by $25 \%$. Moderately clipped plants had greater production than those from other clipping treatments across species. Average threeawn percentage of pot biomass was greater with $B$. gracilis ( $46 \pm 3 \% \mathrm{SE}$ ) than P. smithii ( $38 \pm 3 \% \mathrm{SE}$ ). Fire reduced threeawn from $60 \pm 3 \%$ to $23 \pm 3 \%$ of pot biomass, indicating good potential for rapid reductions in threeawn dominance and restoration of plant diversity with fire.
\end{abstract}

Key Words: Bouteloua, Pascopyrum, prescribed burning, productivity, purple threeawn, simulated grazing

\section{INTRODUCTION}

Purple threeawn (Aristida purpurea Nutt. and varieties) is a native $\mathrm{C}_{4}$ grass capable of invading semiarid and arid rangelands that have experienced intensive disturbance (Klipple and Costello 1960; Evans and Tisdale 1972). The ability of $A$. purpurea to outcompete other native grass species for water and essential nutrients may produce plant communities trending toward A. purpurea monoculture (Evans and Tisdale 1972; Hyder and Bement 1972; Fowler 1990). When A. purpurea is the most prominent member of the plant community, the ability of other native grass species to establish and proliferate is impaired and $A$. purpurea may remain the dominant species for 60+ yr (Costello 1944; Evans and Tisdale 1972; Horn and Redente 1998). Threeawn-dominated plant communities are a serious management concern for both livestock and wildlife because of low palatability and poor forage quality relative to many other native grass species (Meyer and Brown 1985).

Major funding support was provided by the Bureau of Land Management through the Native Landscape Improvement Project.

Mention of any trade name or proprietary product does not constitute a guarantee or warranty by the authors or USDA-ARS; nor does it imply the approval of these products to the exclusion of others.

The USDA-ARS Northern Plains Area is an equal opportunity/affirmative action employer, and all agency services are available without discrimination.

Correspondence: Lance Vermeire, USDA ARS Fort Keogh Livestock and Range Research Laboratory, 243 Fort Keogh Rd, Miles City, MT 59301, USA. Email: lance.vermeire@ ars.usda.gov

Manuscript received 5 October 2012; manuscript accepted 24 January 2013.

(c) 2013 The Society for Range Management
Greenhouse and field trials have revealed numerous characteristics that enhance the competitive ability of $A$. purpurea. Threeawn plants produce a substantial amount of seed that enter the ground quickly and have a high probability of germination (Evans and Tisdale 1972; Fowler 1986). Postgermination, A. purpurea plants begin producing a robust root system, quickly gaining access to soil water and nutrient pools (Evans and Tisdale 1972; Wedin and Tilman 1993; Busso et al. 2001; Perkins and Owens 2003). Furthermore, A. purpurea is rarely grazed (Heitschmidt et al. 1990). In the event $A$. purpurea is defoliated, individuals respond by increasing root mass (Briske et al. 1996). This strategy increases the area the plant can access for soil water and nutrients. Threeawn shoots have a high shoot C:N ratio (Vinton and Burke 1995; Horn 1996), which is believed to indicate effective belowground competition with greater ability to absorb soil nutrients, particularly nitrogen (Tilman 1982; Tilman and Wedin 1991). Understanding the competitive response and effect of $A$. purpurea is the first step toward identifying management tools that can be used to reduce threeawn.

Fire and grazing are naturally occurring processes with which grasslands throughout the world evolved (Axelrod 1985). From a management perspective, prescribed fire and grazing can be utilized to maintain productive plant communities (Fuhlendorf and Engle 2004; Vermeire et al. 2008; Vermeire et al. 2011). A. purpurea is avoided by most herbivores (Klipple and Costello 1960; Heitschmidt et al. 1990), but may be negatively impacted by fire (Trlica and Schuster 1969; Steuter and Wright 1983; Parmenter 2008). A. purpurea has buds near the soil surface and elevated in the crown, making it more vulnerable to fire (Trlica and Schuster 1969) than species with greater proportions of their buds 
deeper in the soil, such as western wheatgrass (Pascopyrum smithii Rydb.), and blue grama (Bouteloua gracilis Willd. ex Kunth). One of the primary characteristics that allows $A$. purpurea to escape grazing pressure is the accumulation of dead material in the crown of plants (Heitschmidt et al. 1990). Fire would also reduce dead material, allowing grazers access to the regrowth of $A$. purpurea. Additionally, regrowth of $A$. purpurea after fire should have more complete nutritional quality relative to A. purpurea which has not been burned (Tracy and McNaughton 1997). A. purpurea's susceptibility to fire damage (Steuter and Wright 1983; Parmenter 2008), improved palatability of surviving plants, and the neutral or positive response of dominant competing species in the northern Great Plains (Vermeire et al. 2011) indicate fire and grazing may be appropriate management tools for threeawndominated plant communities.

The purpose of this study was to develop a more complete understanding of $A$. purpurea response to fire and defoliation in the presence of other native grasses and observe the response of other native grasses to fire and defoliation in the presence of $A$. purpurea. More specifically, we hypothesize that 1 ) fire reduces A. purpurea biomass production, tiller number, and axillary buds; 2) increasing clipping severity reduces A. purpurea biomass production, tiller number, and axillary buds; 3) $A$. purpurea biomass, tiller, and axillary bud production are greater in an interspecific planting than an intraspecific planting; and 4) the combination of fire and clipping reduces A. purpurea biomass relative to competing species.

\section{METHODS}

Seeds of A. purpurea, P. smithii, and B. gracilis were obtained from Native American Seed Farm (Junction, Texas), USDANRCS Bridger Plant Materials Center (Bridger, Montana), and USDA-NRCS Bismarck Plant Materials Center (Bismarck, North Dakota), respectively, during June 2011. Seeds were germinated at $25^{\circ} \mathrm{C}$ with a 12-h photoperiod at Fort Keogh Livestock and Range Research Laboratory in Miles City, MT (lat $46^{\circ} 22^{\prime} 52^{\prime \prime}$, long $105^{\circ} 53^{\prime} 04^{\prime \prime}$ ). On 1 July 2011, seedlings were assigned to one of three paired combinations (B. gracilis/ A. purpurea, P. smithii/A. purpurea, or A. purpurealA. purpurea $)$ and transplanted into plastic pots $(22 \mathrm{~cm}$ diameter $\times 22 \mathrm{~cm}$ height) filled with a 3:1 (volume:volume) mix of washed sand sifted through a $2-\mathrm{mm}$ sieve and potting mix. Sand was sterilized with the use of an electric soil sterilizer. The potting mix (Sunshine Mix 1; Sun Gro Horticulture, Inc., Vancouver, BC) contained sphagnum peat moss, coarse perlite, starter nutrient charge with gypsum, and dolomite limestone. Pots were maintained near field capacity by watering every $2-3$ $\mathrm{d}$ throughout the experimental period with a light shower hose setting for 4-5 s per pot, which allowed for thorough wetting without water running out the bottom of pots. Throughout summer months we utilized natural lighting and greenhouse conditions followed seminatural temperatures, with July being the hottest month ranging from 15.6 to $41.2^{\circ} \mathrm{C}$. Supplemental lighting was used to extend the photoperiod by $3 \mathrm{~h}$ starting on 7 November 2011. Temperatures were lowest throughout December in the greenhouse and were maintained between 4.8 and $25.8^{\circ} \mathrm{C}$.
A factorial arrangement of two fire and four clipping treatments were applied to each of the three species-pair combinations in a completely randomized design with nine replications. Shoots were harvested for final biomass estimates and bud sampling $187 \mathrm{~d}$ after being transplanted into pots. Aboveground biomass for each species at time of fire was estimated by harvesting shoots from additional species-pair combinations (16 B. gracilis, 14 P. smithii, and 57 A. purpurea) not subjected to treatments. Production was estimated as the sum of combusted, clipped, and final biomass. The two distinct measurements of plant mass are hereafter referred to simply as biomass (i.e., final) and production. All harvested biomass was dried at $60^{\circ} \mathrm{C}$ for $48 \mathrm{~h}$ prior to weighing.

Fire treatments consisted of 1) summer fire and 2) no fire. Fire was applied to potted plants on 27 September 2011 with the use of the fire cage method described by Vermeire and Rinella (2009) with a fuel load of $2000 \mathrm{~kg} \cdot \mathrm{ha}^{-1}$ to represent typical summer fire conditions of the northern mixed-grass prairie. Fires burned with an ambient temperature of $26.7-32.2^{\circ} \mathrm{C}, 13-38 \%$ relative humidity, and 11.3 to $16.1 \mathrm{~km} \cdot \mathrm{h}^{-1}$ winds. Six type-K thermocouples insulated with ceramic fiber and Inconel braidings (Omega Engineering, Stamford, CT) were placed 1-3 cm below the soil surface in the center of an A. purpurea plant crown. Thermocouples were connected to a $21 \mathrm{X}$ micrologger with a CR23X storage module (Campbell Scientific, Logan, UT), which was connected to a laptop computer to record timetemperature profiles at 1-s intervals during treatment. Thermocouple data were used to determine duration of temperatures greater than $60^{\circ} \mathrm{C}$ (duration), maximum temperature, and the sum of the products of time and temperature greater than $60^{\circ} \mathrm{C}$ (degree-seconds) to estimate heat dosage. At the time of fire, $A$. purpurea and B. gracilis had reached the seed-head stage of development, but remained green. P. smithii remained in the vegetative stage throughout the study.

Clipping treatments consisted of 1) no clipping of either plant, 2) no clipping of A. purpurea and moderate clipping of adjacent plants, 3) moderate clipping of $A$. purpurea and severe clipping of adjacent plants, and 4) severe clipping of $A$. purpurea and adjacent plants. One plant was randomly selected and marked with a pin flag to designate which received the more severe clipping treatment when both plants were $A$. purpurea. For A. purpurea and P. smithii, $10-\mathrm{cm}$ and $5-\mathrm{cm}$ stubble heights represent moderate and severe clipping, respectively. For B. gracilis, $6-\mathrm{cm}$ and $3-\mathrm{cm}$ stubble heights represented moderate and severe clipping, respectively. Clipping treatments were applied on 4 November 2011 with the use of hand clippers. Given grazing selection against A. purpurea, clipping treatments were designed to simulate expectations that utilization of A. purpurea would occur to a lesser degree than the competing species and only after availability of the more desired species became limited.

Concurrently with final biomass sampling, a tiller was harvested from each plant in four replications of each species-treatment combination (192 plants). The tillers were cleaned and processed in the Fort Keogh laboratory with the use of microscopic dissection procedures. Total, active, dormant, and dead buds were determined with the use of a double-staining procedure as described by Busso et al. (1989) and Hendrickson and Briske (1997). Axillary buds were stained with a 2,3,5-triphenyl tetrazolium chloride (TTC) solution to 
determine viability. Tillers were submerged in TTC solution for a 24-h period in a completely dark environment. Buds were considered active when stained a bright pink. If dormant buds were present, the tiller was submerged into $0.25 \%$ Evan's Blue solution for $20 \mathrm{~min}$ at room temperature following TTC staining to verify dormancy or death. Buds that did not stain with either TTC or Evan's blue and maintained their white pigment were considered dormant (Busso et al. 1989). Dead buds were readily identified from dormant buds by staining a deep blue (Gaff and Okong'o-ogola 1971). Active and dormant buds were summed then multiplied by tiller counts and reported as number of live axillary buds per plant.

The maximum number of buds per tiller was based on the cumulative sum of four bud categories: 1 ) buds that had grown out to form tillers, rhizomes, or stolons (live or dead), 2) missing buds based on the occurrence of bud scars, 3) leaf scars, and 4) existing visible buds (Hendrickson and Briske 1997). Leaf scars located at the point of sheath attachment to the tiller base identified the position of potential buds when a bud scar could not be located. Only those axillary buds located on the basal $20 \mathrm{~mm}$ of the tiller (crown region) were evaluated. We recognize that some species may not possess buds in all leaf axils (Mueller and Richards 1986).

Maximum temperature, duration of heat $>60^{\circ} \mathrm{C}$, and heat dosage (degree-seconds $>60^{\circ} \mathrm{C}$ ) were each tested as predictor variables for mortality of burned A. purpurea with logistic regression with the use of SAS LOGISTIC (Hosmer and Lameshow 2000; Menard 2002). A. purpurea and competing plants had different clipping treatments and were analyzed separately in what is hereafter discussed as Experiment I (A. purpurea) and Experiment II (competing plant). Models for biomass, biomass production, tiller counts, and axillary buds were analyzed with the use of analysis of variance ANOVA with the MIXED procedure of SAS (Littell et al. 1996) for both experiments. Models for Experiment I and the proportion of pot biomass comprised of A. purpurea tested the main effects of species combination, fire, clipping treatment, and their interactions. Models for Experiment II (A. purpurea, $B$. gracilis, and $P$. smithii grown with A. purpurea) contained terms for species, fire, clipping treatment, and their interactions. Mean separations were determined with $t$ tests of pairwise comparisons with the use of the PDIFF option with the LSMEANS statement following significant $F$ tests on main effects or interactions, and significance for all tests was declared at $\alpha=0.05$. All results are reported as mean \pm standard error of the mean (SEM).

\section{RESULTS}

\section{Experiment I. Aristida purpurea Response}

Mortality was 36\% (52/144) for A. purpurea plants exposed to fire and resulted in substantial reductions of biomass for this species. None of the 144 nonburned A. purpurea plants died. Mortality increased with duration of heat $(P<0.01)$ and heat dosage $(P<0.01$; Fig. 1$)$. However, maximum temperature was not a good predictor of $A$. purpurea mortality $(P>0.24)$. Duration of heat was the best predictor of plant mortality, with the C-statistic (0.71) indicating the model correctly assigned greater probability of mortality for $71 \%$ of all pairs where one
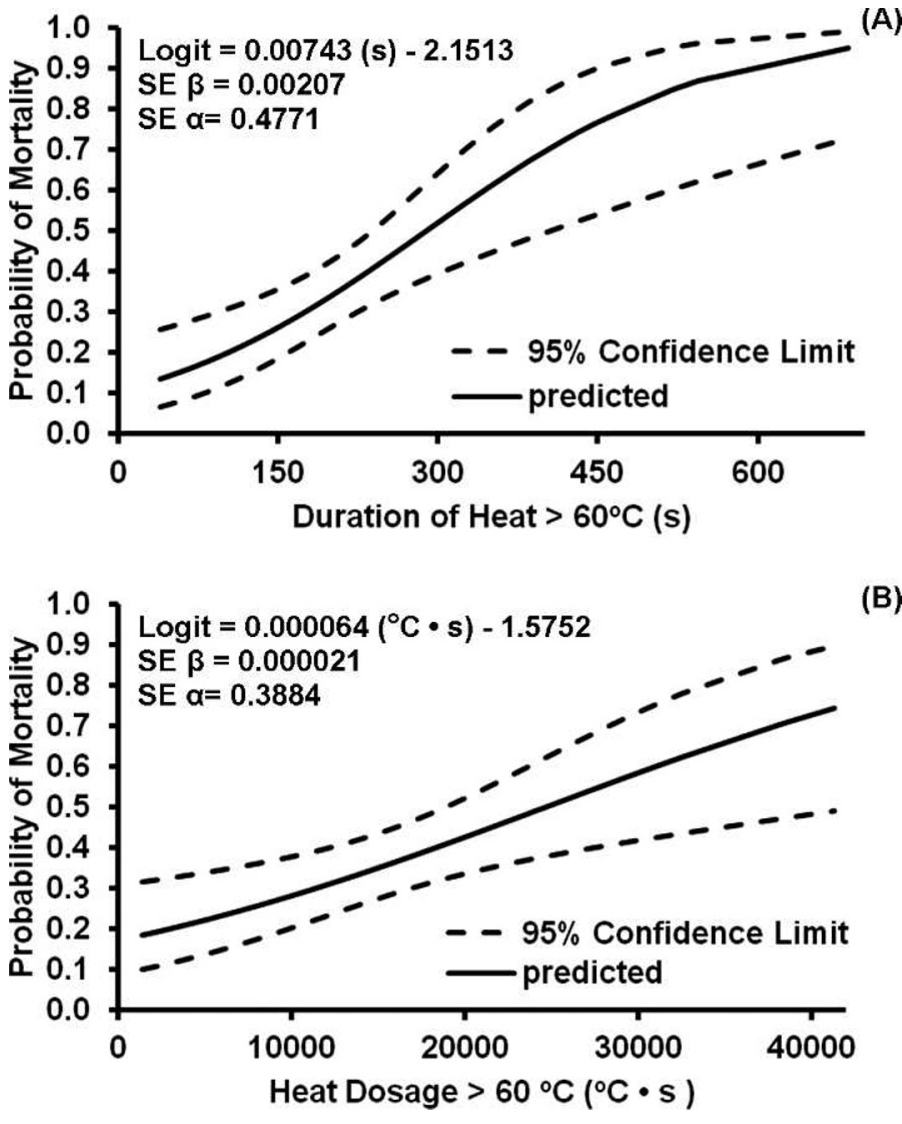

(B)

Figure 1. Predicted mortality and $95 \%$ confidence intervals for an Aristida purpurea individual based on $\mathbf{A}$, duration of heat greater than $60^{\circ} \mathrm{C}$ at the soil surface; and $\mathbf{B}$, heat dosage measured as degree-seconds greater than $60^{\circ} \mathrm{C}$. Probability of mortality $=\left(e^{\alpha+\beta x}\right) \cdot\left(1+e^{\alpha+\beta x}\right)^{-1}$.

plant lived and one died. The Hosmer-Lameshow test also indicated the model fit the data well $(P>0.17)$. A. purpurea individuals had a $50 \%$ probability of survival when temperatures were greater than $60^{\circ} \mathrm{C}$ for $5 \mathrm{~min}$. Heat dosage closely followed duration of heat as a reliable predictor of plant mortality, with a $C$-statistic of 0.64 and a good fit for the model $(P>0.10)$. Unless otherwise stated, all other results were based on surviving plants only.

Fire and clipping interacted in their effects on A. purpurea biomass at the end of the experiment $(P<0.01$; Table 1$)$. As expected, nonburned plants that were moderately or severely clipped had less biomass than nonclipped plants. Surprisingly, biomass was less for nonburned plants when their neighbor was clipped than when neither plant was clipped. Biomass did not differ among clipping treatments for burned plants. Burned plants, across clipping treatments, had less $A$. purpurea biomass than nonburned plants that were not clipped.

Fire effects on production varied by species combination $(P<0.04)$. A. purpurea grown with B. gracilis produced $22 \%$ less biomass when burned and $21 \%$ less than non-burned $A$. purpurea grown with $A$. purpurea (Fig. 2). Fire did not reduce production of $A$. purpurea when planted with $P$. smithii or $A$. purpurea (Fig. 2). Production was greatest when neither plant was clipped and least when the competing species was 
Table 1. Fire and clipping effects on mean (SEM) tiller number and biomass of Aristida purpurea (Experiment I) and competing species (Experiment II).

\begin{tabular}{lccc}
\hline \multicolumn{1}{c}{ Measurement } & Clipping $^{1}$ & No fire & Fire \\
\hline Experiment I & & & \\
Biomass $\left(\mathrm{g} \cdot\right.$ plant $\left.^{-1}\right)$ & $\mathrm{NN}$ & $4.46(0.23) \mathrm{a}^{2}$ & $0.88(0.28) \mathrm{cd}^{3}$ \\
& $\mathrm{NM}$ & $2.94(0.23) \mathrm{b}$ & $0.75(0.30) \mathrm{d}$ \\
& $\mathrm{MS}$ & $1.53(0.23) \mathrm{c}$ & $0.81(0.30) \mathrm{cd}$ \\
& $\mathrm{SS}$ & $1.00(0.23) \mathrm{cd}$ & $0.51(0.31) \mathrm{d}$ \\
Tillers $(n)$ & $\mathrm{NN}$ & $28(1.6) \mathrm{a}$ & $15(1.6) \mathrm{d}$ \\
& $\mathrm{NM}$ & $24(1.6) \mathrm{ab}$ & $17(1.6) \mathrm{cd}$ \\
& $\mathrm{MS}$ & $23(1.6) \mathrm{ab}$ & $18(1.6) \mathrm{cd}$ \\
& SS & $21(1.6) \mathrm{bc}$ & $17(1.6) \mathrm{cd}$
\end{tabular}

Experiment II

$\begin{array}{llll}\text { Biomass }\left(\mathrm{g} \cdot \text { plant }^{-1}\right) & \text { NN } & 3.44(0.16) \mathrm{a} & 1.18(0.17) \mathrm{c} \\ & \text { MN } & 2.00(0.16) \mathrm{b} & 1.21(0.18) \mathrm{c} \\ & \text { SM } & 0.93(0.16) \mathrm{cd} & 0.73(0.20) \mathrm{cd} \\ & \text { SS } & 0.96(0.16) \mathrm{cd} & 0.63(0.18) \mathrm{d}\end{array}$

${ }^{1} \mathrm{NN}=$ no clipping of either plant, $\mathrm{NM}=$ no clipping of $A$. purpurea and moderate clipping of adjacent species, $\mathrm{MS}=$ moderate clipping of $A$. purpurea and severe clipping of adjacent species, $\mathrm{SS}=$ severe clipping of $A$. purpurea and adjacent species.

${ }^{2}$ Means within measurement with a common letter do not differ $(P>0.05)$.

${ }^{3}$ Exclusion of killed plants from biomass data reduced $n$ for burned fire $\times$ clipping means from 27 to $18,16,16$, and 15 for NN, NM, MS, and SS, respectively.

moderately clipped, or when both plants were severely clipped $(P<0.04$; Table 2).

Fire and clipping interacted in their effects on A. purpurea tiller numbers $(P<0.05$; Table 1$)$. Severe clipping reduced tiller numbers for nonburned plants compared to when neither plant was clipped. Tiller counts of burned plants did not differ among clipping treatments, all of which had fewer tillers than nonburned plants that were not clipped or moderately clipped. Severe clipping yielded similar A. purpurea tiller counts regardless of fire. Fire decreased the number of live axillary buds per plant by $25 \%(P<0.01)$. A purpurea produced $75 \pm 5$ axillary buds without fire and $56 \pm 5$ axillary buds with fire. Species combinations alone did not affect A. purpurea biomass $(P>0.68)$, axillary buds $(P>0.17)$, or tiller numbers $(P>0.14)$.

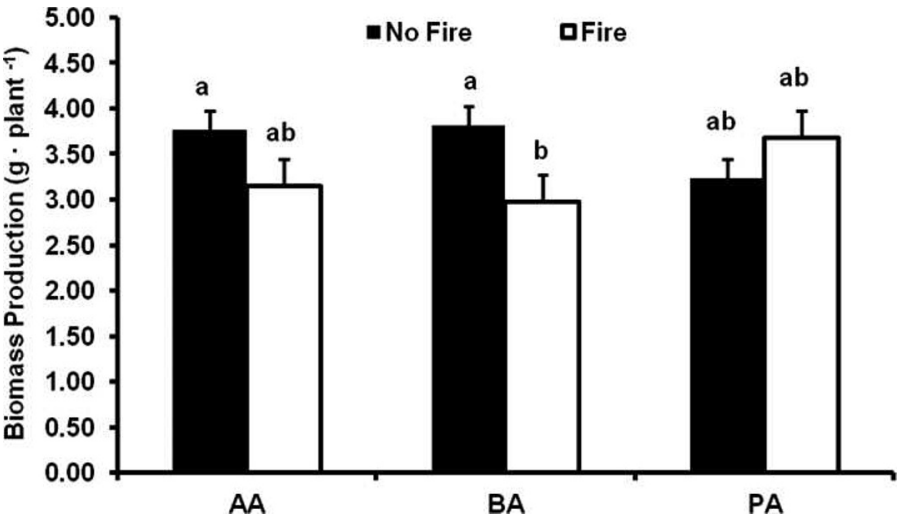

Figure 2. Mean Aristida purpurea biomass production and SEM bars in response to fire and species combination. $\mathrm{A}=$ A. purpurea, $\mathrm{B}=$ Bouteloua gracilis, and $\mathrm{P}=$ Pascopyrum smithii. Exclusion of killed plants from production data reduced $n$ for burned fire $\times$ species combination means from 36 to 27, 19, and 19 for AA, BA, and PA, respectively. Means with a common letter do not differ $(P>0.05)$.

\section{Experiment II. Competing Plant Responses}

Fire effects on biomass varied by species $(P<0.01$; Table 3$)$. Fire reduced biomass of $B$. gracilis by $60 \%$ and $A$. purpurea by $61 \%$. Biomass was similar between burned and nonburned $P$. smithii. Clipping effects on biomass varied by fire treatment $(P<0.01)$ and by species $(P<0.03)$. Without fire, moderately clipped plants with nonclipped neighbors had less biomass than those with neither plant clipped and more biomass than severely clipped plants (Table 1). However, when plants were burned, biomass was reduced only when both plants were severely clipped relative to moderately and nonclipped plants. Severe clipping reduced $A$. purpurea biomass compared to moderate or no clipping and any clipping reduced B. gracilis biomass (Fig. 3). Biomass of P. smithii decreased with increasing clipping intensity.

Fire effects on biomass production varied by species $(P<0.01$; Table 3$)$. Fire reduced biomass production of $P$. smithii by $31 \%$ and A. purpurea by $27 \%$, whereas B. gracilis production was similar between burned and nonburned plants. A. purpurea was most productive among nonburned plants, but with fire, production was similar to that of $B$. gracilis.

Table 2. Effects of clipping intensity on mean biomass production, axillary buds, and tillers for Aristida purpurea (Experiment I) and competing species (Experiment II).

\begin{tabular}{|c|c|c|c|c|c|c|}
\hline \multirow[b]{2}{*}{ Measurement } & \multicolumn{5}{|c|}{ Clipping treatment $^{1}$} & \multirow[b]{2}{*}{$P$ value } \\
\hline & NN & NM & MS & SS & SEM & \\
\hline \multicolumn{7}{|l|}{ Experiment I } \\
\hline Production $\left(\mathrm{g} \cdot\right.$ plant $\left.^{-1}\right)$ & $3.88 a^{3}$ & $3.06 \mathrm{~b}$ & $3.51 \mathrm{ab}$ & $3.29 \mathrm{~b}$ & 0.22 & 0.04 \\
\hline Axillary buds ${ }^{2}(n)$ & 75 & 68 & 64 & 54 & 6.7 & 0.18 \\
\hline \multicolumn{7}{|l|}{ Experiment II } \\
\hline Production, $\left(\mathrm{g} \cdot\right.$ plant $\left.^{-1}\right)$ & $3.18 b$ & $3.78 \mathrm{a}$ & $3.13 b$ & $3.26 b$ & 0.17 & 0.02 \\
\hline Axillary buds $(n)$ & 75 & 80 & 82 & 67 & 9.1 & 0.66 \\
\hline Tillers $(n)$ & 23 & 21 & 20 & 20 & 1.3 & 0.39 \\
\hline
\end{tabular}

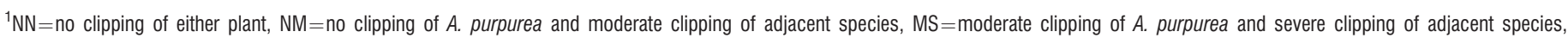
$\mathrm{SS}=$ severe clipping of $A$. purpurea and adjacent species.

${ }^{2}$ Axillary buds include dormant and active bud estimates.

${ }^{3}$ Means within measurement with a common letter do not differ $(P>0.05)$. 
Table 3. Fire effects on mean (SEM) biomass and production for competing species (Experiment II).

\begin{tabular}{clll}
\hline \multicolumn{1}{c}{ Measurement } & \multicolumn{1}{c}{ Species } & No fire & \\
\hline Biomass, $\left(\mathrm{g} \cdot\right.$ plant $\left.^{-1}\right)$ & Aristida purpurea & $2.56(0.14) \mathrm{a}^{1}$ & Fire \\
& Bouteloua gracillis & $1.38(0.14) \mathrm{bc}$ & $1.01(0.16) \mathrm{c}$ \\
& Pascopyrumsmithii & $1.55(0.14) \mathrm{b}$ & $0.55(0.15) \mathrm{d}$ \\
Production $\left(\mathrm{g} \cdot\right.$ plant $\left.^{-1}\right)$ & A. purpurea & $4.59(0.18) \mathrm{a}$ & $1.26(0.16) \mathrm{bc}$ \\
& B. gracillis & $3.24(0.18) \mathrm{b}$ & $3.35(0.21) \mathrm{b}$ \\
& P. smithii & $3.23(0.18) \mathrm{b}$ & $2.38(0.20) \mathrm{b}$ \\
\hline
\end{tabular}

${ }^{1}$ Means within measurement with a common letter do not differ $(P>0.05)$.

Moderately clipped plants had greater production than those from other clipping treatments across species (Table 2).

Tiller counts increased $(P<0.01)$ from $P$. smithii to $A$. purpurea, then $B$ gracilis $\left(10,22\right.$, and $31 \pm 1$ tiller $\cdot$ plant $\left.^{-1}\right)$ and axillary buds were nearly twice as abundant $(P<0.01)$ for $B$. gracilis (112 buds) as they were for $P$. smithii (53 buds) or $A$. purpurea ( $63 \pm 8$ buds). Fire reduced tillers across species from 23 to $18 \pm 1$ tiller $\cdot$ plant $^{-1}(P<0.01)$. There were no clipping treatment effects on tiller number $(P>0.38)$. Dormant and active axillary bud counts were similar across fire $(P>0.16)$ and clipping $(P>0.66)$ treatments.

\section{Proportional A. purpurea Biomass}

Excluding killed plants, the percentage of pot biomass comprised of $A$. purpurea was greater $(P<0.01)$ when grown with $B$. gracilis $(57 \pm 3 \%)$ than with $P$. smithii $(45 \pm 3 \%)$. Fire reduced $A$. purpurea from $60 \pm 2 \%$ to $41 \pm 4 \%$ of the pot biomass $(P<0.01)$. Percentage of pot biomass was similar across clipping treatments $(P>0.28)$.

Including plants that were killed, A. purpurea comprised a greater $(P<0.05)$ percentage of the pot biomass when grown with $B$. gracilis $(46 \pm 3 \%)$ than with $P$. smithii $(38 \pm 3 \%)$. Fire reduced $A$. purpurea from $60 \pm 3 \%$ to $23 \pm 3 \%$ of the pot biomass $(P<0.01)$. The inclusion of killed plants indicated a clipping effect $(P<0.04)$. No treatments differed from nonclipped plants with nonclipped neighbors $(41 \pm 4 \%)$. However, severe clipping of both plants reduced the percentage of pot

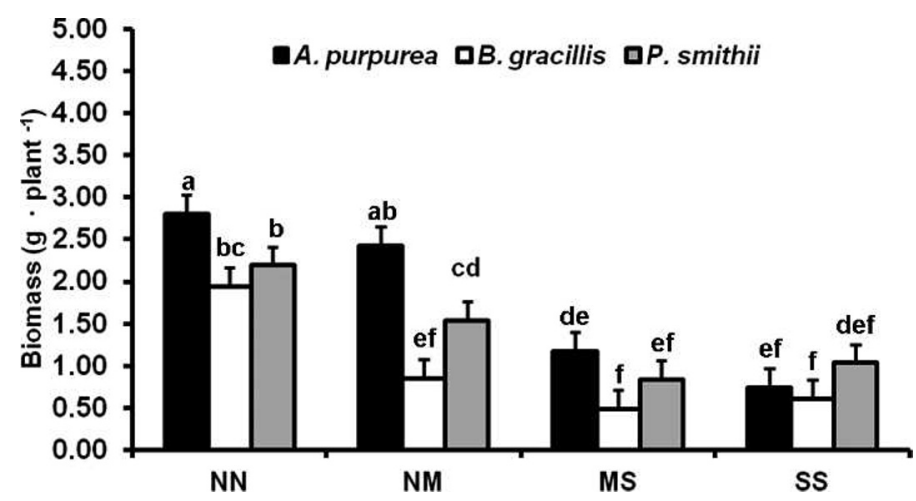

Figure 3. Mean biomass and SEM bars by species grown with Aristida purpurea and clipping treatment. Clipping treatments consisted of $\mathrm{NN}=\mathrm{no}$ clipping of either plant, $\mathrm{NM}=$ no clipping of $A$. purpurea and moderate clipping of adjacent species (NM), $\mathrm{MS}=$ moderate clipping of $A$. purpurea and severe clipping of adjacent species (MS), $\mathrm{SS}=$ severe clipping of $A$. purpurea and adjacent species, respectively. Means with a common letter do not differ $(P>0.05)$. biomass attributed to A. purpurea $(32 \pm 4 \%)$ compared to nonclipped plants with moderately clipped neighbors $(46 \pm 4 \%)$ and moderately clipped plants with severely clipped neighbors $(48 \pm 4 \%)$.

\section{DISCUSSION}

We observed considerable mortality of A. purpurea when exposed to fire, and heat duration and dosage were excellent predictors of this response. Data support hypothesized reductions in A. purpurea biomass production and axillary buds due to fire. However, our data demonstrate that fire alone did not directly reduce $A$. purpurea tiller production for surviving plants. As hypothesized, severe clipping reduced A. purpurea production and tiller number relative to no clipping at all, but no clipping of $A$. purpurea and moderate clipping of its neighbor caused a similar reduction in productivity. Results do not support anticipated increases in biomass, tiller production, and axillary bud production of A. purpurea in interspecific compared to intraspecific plantings. The only case in which species combination affected production, tiller number, or axillary buds was that fire reduced production of $A$. purpurea when grown with $B$. gracilis. Our data partially support the hypothesis that the combination of fire and clipping decreases $A$. purpurea biomass relative to $B$. gracilis and $P$. smithii biomass composition in that there was a strong fire effect, but clipping effects were only observed when including plants killed by fire.

Effects of fire on A. purpurea production align with previous work on perennial threeawns throughout the High Plains of Texas (Trlica and Schuster 1969; Steuter and Wright 1983) and the short-grass steppe in the Chihuahuan Desert (Parmenter 2008). Postfire reduction of $A$. purpurea plant size in the Chihuahuan Desert demonstrated more than 4 yr were required to recover prefire basal cover fully (Parmenter 2008). However, postfire drought was speculated to have contributed to the slow recovery of A. purpurea. Nevertheless, fire and drought may provide opportunities for species, such as $B$. gracilis or $P$. smithii, that evolved under this type of regime in semiarid environments to thrive in a previously A. purpurea-dominated site.

In addition to reductions in A. purpurea production, axillary bud and tiller numbers were also reduced by fire. Inhibiting vegetative reproduction of $A$. purpurea could be a crucial management factor because of bunchgrasses' capacity for rapid biomass recovery, which primarily occurs by abundant tillering from preformed axillary buds (Fidelis et al. 2012). Caespitose 
grasses, such as $A$. purpurea, also possess the ability to increase root mass, accumulate nutrients underneath the crown, and rapidly expend released nutrients to increase tillering (Briske et al. 1996; Derner et al. 1997). Therefore, limiting the reproductive potential of the $A$. purpurea bud bank by decreasing axillary bud production reduces an individual's ability to recover rapidly within a growing season. Furthermore, decreasing the amount of axillary buds reduces the potential for new A. purpurea tillers to form from pre-existing tillers, providing a greater opportunity for more fire-resilient species, such as $B$. gracilis or $P$. smithii, to become established.

Because of the resistance and resiliency of $B$. gracilis and $P$. smithii to fire (Vermeire et al. 2011), we expected to elicit increased production responses of these more desirable, native perennial grass species. The observed reductions in $P$. smithii production may be a short-term response given the timing of postfire sampling. Pascopyrum smithii production has been shown to more than double on burned sites the second year following fire (Vermeire et al. 2011). In the same study, $P$. smithii standing crop was $47 \%$ greater for burned than nonburned sites following a summer fire with a wet spring in the northern Great Plains. Our observation of similar biomass production between burned and nonburned B. gracilis is consistent with previous research illustrating consistently high allocation of resources belowground throughout the growing season, short-shoot growth form, and high regrowth potential (Menke and Trlica 1981).

We expected defoliation of either B. gracilis or $P$. smithii to release resources available for increased growth of $A$. purpurea, as suggested by competition theory (Wardle et al. 1999). However, we observed reduced A. purpurea production when the more palatable neighboring species were moderately defoliated and increased production of neighboring species when they were moderately defoliated. The mechanism responsible for this result is not clear, based on the data collected. Defoliation of $A$. purpurea has been shown to shift carbon allocation from shoots to roots (Briske et al. 1996; Busso et al. 2001), and indirect results of defoliated neighboring plants (Briske and Hendrickson 1998) may have further prioritized capture of belowground space and resources. Thus, energy invested toward construction and maintenance of extensive root densities may compromise $A$. purpurea's short-term ability to increase aboveground biomass. Alternatively, additional resource demand by the defoliated neighbor plants could have increased belowground competition.

The reduced biomass production following moderate clipping of neighboring species could be a short-term response. For example, Busso et al. (2001) reported positive correlations between root length, density, and total biomass production on nondefoliated A. purpurea plants. Further, Smith and Knapp (2003) reported as much as a 2 -yr delay in aboveground responses due to neighbor removal in $\mathrm{C}_{4}$-dominated grassland. In our study, $61 \mathrm{~d}$ may not have been sufficient time for $A$. purpurea to respond positively to neighbor defoliation, but undoubtedly allowed expression of negative effects. Further research is needed to elucidate this interaction, including the time for which these reductions can be sustained. There is evidence that slight shifts in aboveground species dominance can provide advantageous opportunities for $B$. gracilis and $P$. smithii to increase production postfire (Vermeire et al. 2011). Thus, sustainable changes in species composition could be expected, given the findings of our current work. It is also important to point out that the impacts of neighbor clipping on A. purpurea tiller numbers were different in the presence versus absence of fire. In the presence of fire, defoliation does not play an important role in reducing tiller counts of A. purpurea, and in the absence of fire, clipping reduced tiller counts.

Defoliation effects on $B$. gracilis and P. smithii in this study were consistent with other studies (Milchunas et al. 1990; Manley et al. 1997; Hart and Ashby 1998) and suggest these species are capable of persisting with $A$. purpurea. Production of $B$. gracilis and $P$. smithii biomass following moderate defoliation demonstrates these species' potential to resist competitive exclusion by the more competitive $A$. purpurea. Other research has reported that certain responses to disturbance may suppress the overall greater competitive ability of a dominant species, potentially displacing dominant species (Briske and Hendrickson 1998; Hendon and Briske 2002). Multiple studies have reported that diverse rangelands are resilient to the effects of postfire grazing, such as tallgrass prairie (Fuhlendorf and Engle 2004), sagebrush steppe (Bruce et al. 2007; Bates et al. 2009), and semiarid grasslands (Guevara et al. 1999; Drewa and Havstad 2001). More specifically, deferment of grazing during the first postburn growing season in shortgrass steppe has had no effect on forage production compared to sites grazed at a moderate stocking rate (Augustine et al. 2010).

\section{MANAGEMENT IMPLICATIONS}

Restoring naturally occurring processes, such as fire and grazing in the northern Great Plains, is consistent with management strategies that account for processes to which these species are adapted. Therefore, it is doubtful that employing these types of strategies will result in complete eradication of $A$. purpurea, but instead will most likely increase grazing capacity and native plant diversity. Our results demonstrate potential for prescribed burning and grazing to decrease $A$. purpurea biomass and encourage increases in abundance of other native plant species to disrupt nearmonocultures of $A$. purpurea. The degree to which $A$. purpurea-dominated communities are affected by prescribed burning and grazing remains unknown. However, our results indicate that $A$. purpurea biomass reductions due to fire and postfire defoliation may be important factors in reducing $A$. purpurea abundance. Future research should focus on timing and intensity of prescribed burning in conjunction with postfire grazing strategies on rangelands in order to alter A. purpureadominated sites.

\section{LITERATURE CITED}

Augustine, D. J., J. D. Derner, and D. G. Milchunas. 2010. Prescribed fire, grazing, and herbaceous plant production in shortgrass steppe. Rangeland Ecology \& Management 63:317-323.

AxelRod, D. 1985. Rise of the grassland biome, central North America. The Botanical Review 51:163-201. 
Bates, J. D., E. C. Rhodes, K. W. Davies, and R. Sharp. 2009. Postfire succession in big sagebrush steppe with livestock grazing. Rangeland Ecology \& Management 62:98-110.

Briske, D. D., T. W. Boutton, and Z. Wang. 1996. Contribution of flexible allocation priorities to herbivory tolerance in C3 perennial grasses: an evaluation with ${ }^{13} \mathrm{C}$ labeling. Oecologia 105:151-159.

BRISKE, D. D., AND J. R. HendRICKSon. 1998. Does selective defoliation mediate competitive interactions in a semiarid savanna? A demographic field evaluation. Journal of Vegetation Science 9:611-622.

Bruce, L. B., B. Perryman, K. Conley, and K. McAdoo. 2007. Case study: grazing management on seeded and unseeded post fire public rangelands. The Professional Animal Scientist 23:285-290.

Busso, C. A., D. D. Briske, and V. Olalde-Portugal. 2001. Root traits associated with nutrient exploitation following defoliation in three coexisting perennial grasses in a semi-arid savanna. Oikos 93:332-342.

Busso, C. A., R. J. Mueller, and J. H. Richards. 1989. Effects of drought and defoliation on bud viability in two caespitose grasses. Annals of Botany 63:477-485.

Costello, D. F. 1944. Natural revegetation of abandoned plowed land in the mixed prairie association of northeastern Colorado. Ecology 25:312-326.

Derner, J. D., D. D. BriSKE, And T. W. Boutton. 1997. Does grazing mediate soil carbon and nitrogen accumulation beneath C4 perennial grasses along an environmental gradient? Plant Soil 191:147-156.

Drewa, P. B., And K. M. Havstad. 2001. Effects of fire, grazing and the presence of shrubs on Chihuahuan desert grasslands. Journal of Arid Environments 48:429 443

Evans, G. R., And E. W. Tisdale. 1972. Ecological characteristics of Aristida longiseta and Agropyron spicatum in west-central Idaho. Ecology 53:137-142.

Fidelis, A., C. C. Blanco, S. C. Muller, V. D. Pillar, and J. Pfadenhauer. 2012. Shortterm changes caused by fire and mowing in Brazilian Campos grasslands with different long-term fire histories. Journal of Vegetation Science 23:552-562.

FowLER, N. L. 1986. Microsite requirements for germination and establishment of three grass species. American Midland Naturalist 115:131-145.

FowLER, N. L. 1990. The effects of competition and environmental heterogeneity on three coexisting grasses. Journal of Ecology 78:389-402.

FuHLendorf, S. D., AND D. M. Engle. 2004. Application of the fire-grazing interaction to restore a shifting mosaic on tallgrass prairie. Journal of Applied Ecology 41:604614

GafF, D. F., AND O. OKong'O-OGOLA. 1971. The use of non-permeating pigments for testing the survival of cells. Journal of Experimental Botany 22:756-758.

Guevara, J. C., C. R. Stasi, C. F. Wuilloud, and 0. R. Estevez. 1999. Effects of fire on rangeland vegetation in south-western Mendoza plains (Argentina) composition, frequency, biomass, productivity and carrying capacity. Journal of Arid Environments 41:27-35.

Heitschmidt, R. K., D. D. Briske, and D. L. Price. 1990. Pattern of interspecific tiller defoliation in a mixed-grass prairie grazed by cattle. Grass Forage Science $45: 215-222$

HART, R. H., AND M. M. AshBy. 1998. Grazing intensities, vegetation, and heifer gains: 55 years on shortgrass. Journal of Range Management 51:392-398.

Hendon, B. C., AND D. D. Briske. 2002. Relative herbivory tolerance and competitive ability in two dominant:subordinate pairs of perennial grasses in a native grassland. Plant Ecology 160:43-51.

Hendrickson, J. R., And D. D. Briske. 1997. Axillary bud banks of two semiarid perennial grasses: occurrence, longevity, and contribution to population persistence. Oecologia 110:584-591.

Horn, B. E. 1996. Influence of available soil nitrogen on an old-field plant community [dissertation]. Fort Collins, C0, USA: Colorado State University. 117 p.

Horn, B. E., and E. F. Redente. 1998. Soil nitrogen and plant cover of an old-field on the shortgrass steppe in southeastern Colorado. Arid Soil Research and Rehabilitation 12:193-206.
Hosmer, D. W., and S. Lameshow. 2000. Applied logistic regression. 2nd ed. New York, NY, USA: John Wiley \& Sons. $375 p$

HydER, D. N., AND R. E. Bement. 1972. Controlling red threeawn on abandoned cropland with ammonium nitrate. Journal of Range Management 25:443-446.

KLIPPLE, G. E., AND D. F. Costello. 1960. Vegetation and cattle responses to different intensities of grazing on shortgrass ranges of the central Great Plains. Washington, DC, USA: USDA. Technical Bulletin 1216. 82 p.

LitTell, R. C., G. A. Milliken, W. W. Stroup, and R. D. Wolfinger. 1996. SAS system for mixed models. Cary, NC, USA: SAS Institute. $633 \mathrm{p}$.

Manley, W. A., R. H. Hart, M. J. Samuel, M. A. Smith, J. W. Waggoner, and J. T. Manley. 1997. Vegetation, cattle, and economic responses to grazing strategies and pressures. Journal of Range Management 50:638-646.

Menard, S. 2002. Applied logistic regression analysis. 2nd ed. Thousand Oaks, CA, USA: Sage. $111 p$

MenKE, J. W., AND M. J. TRLiCA. 1981. Carbohydrate reserve, phenology, and growth cycles of nine Colorado range species. Journal of Range Management 34:269277.

MeYer, M. W., AND R. D. Brown. 1985. Seasonal trends in the chemical composition of ten range plants in south Texas. Journal of Range Management 38:154-157.

Mllchunas, D. G., W. K. Lauenroth, P. L. Chapman, and M. K. Kazempour. 1990. Community attributes along a perturbation gradient in a shortgrass steppe. Journal of Vegetation Science 1:375-384.

Mueller, R. J., AND J. H. Richards. 1986. Morphological analysis of tillering in Agropyron spicatum and Agropyron desertorum. Annals of Botany 58:911-921.

Parmenter, R. R. 2008. Long-term effects of a summer fire on desert grassland plant demographics in New Mexico. Rangeland Ecology \& Management 61:156-168.

Perkins, S. R., And M. K. Owens. 2003. Growth and biomass allocation of shrub and grass seedlings in response to predicted changes in precipitation seasonality Plant Ecology 168:107-120.

Smith, M. D., and A. K. KNapp. 2003. Dominant species maintain ecosystem function with nonrandom species loss. Ecology Letters 6:509-517.

Steuter, A. A., And H. A. Wright. 1983. Spring burning effects on redberry junipermixed grass habitats. Journal of Range Management 36:161-164.

TILMAN, D. 1982. Resource competition and community structure. Princeton, NJ, USA: Princeton University Press. 296 p.

TILMAn, D., AND D. Wedin. 1991. Plant traits and resource reduction for five grasses growing on a nitrogen gradient. Ecology 72:685-700.

Tracy, B. F., and S. J. McNaughton. 1997. Elk grazing and vegetation responses following a late season fire in Yellowstone National Park. Plant Ecology 130:111119.

Trlica, M. J., And J. L. Schuster. 1969. Effects of fire on grasses of the Texas high plains. Journal of Range Management 22:329-333.

Vermeire, L. T., R. K. Heitschmidt, and M. R. Haferkamp. 2008. Vegetation response to seven grazing treatments in the Northern Great Plains. Agriculture Ecosystems \& Environment 125:111-119.

Vermeire, L. T., AND M. J. Rinella, 2009. Fire alters emergence of invasive plant species from soil surface-deposited seeds. Weed Science 57:304-310.

Vermeire, L. T., J. L., Crowder, and D. B. Wester. 2011. Plant community and soil environment response to summer fire in the Northern Great Plains. Rangeland Ecology \& Management 64:37-46.

VINTON, M. A., AND I. C. BuRKE. 1995. Interactions between individual plant species and soil nutrient status in shortgrass steppe. Ecology 76:1116-1133.

Wardle, D. A., K. I. Bonner, G. M. Barker, G. M. Yeates, K. S. Nicholson, R. D. Bardgett, R. N. Watson, and A. Ghanı. 1999. Plant removals in perennial grassland: vegetation dynamics, decomposers, soil biodiversity, and ecosystem properties. Ecological Monographs 69:535-568.

WEDIN, D., AND D. TILMAN. 1993. Competition among grasses along a nitrogen gradient: initial conditions and mechanisms of competition. Ecological Monographs 63:199-229. 